\title{
Pandemia y orden público: el espacio de la protesta
}

\author{
Pandemic and public order: the space of the protest
}

\begin{abstract}
Pablo Pérez Navarro*
Resumo: Uno de los aspectos más llamativos de las respuestas a la crisis del covid19 es el grado de securitización y militarización de las políticas de salud pública a nivel global que las acompaña. Tomando como guía el discurso de la OMS y la figura del estado de excepción, este texto pretende interrogar el reordenamiento moral y biopolítico del espacio público que se deriva de ese proceso, teniendo en cuenta la diferenciación de sus efectos en términos de exposición al riesgo y la violencia dependiendo de variables raciales, de género y de clase, entre otras. Para ello tomo ejemplos de diferentes contextos geográficos y políticos sobre el trasfondo de los últimos ciclos de la protesta urbana.
\end{abstract}

Palavras-chave: Biopolítica; Ordem público; Estado de excepción; Protesta urbana; Securitización; Covid 19

Abstract: One of the most striking issues arising from state responses to the covid19 crisis is the level of securitization and militarization of public health policies they imply at the global level. Drawing on WHO's discourse and the figure of the state of exception, this text constitutes an attempt to interrogate the moral and biopolitical reordering of public space involved, taking into account the differentiated levels of risk and exposure to violence this process entails depending on gender, race and class, among other variables. For that purpose, 1 take examples from various political and geographic contexts over the background of the last cycles of urban protest.

Keywords: Biopolitics; Public order; State of exception; Urban protest; Securitization; Covid 19

La propia enfermedad se convierte en una metáfora. Entonces, en nombre de la enfermedad (es decir, usándola como metáfora), ese horror se impone sobre otras cosas. Susan Sontag

Como en las grandes revoluciones, la pandemia impone su propio calendario. De ahí que parezcan tan lejanas las protestas que, desde Hong Kong hasta Chile, pasando por Irán, Italia, Francia, Ecuador, El Líbano o Haití, entre otros muchos lugares, sacudieron el globo en 2019. El contraste es especialmente notable teniendo en cuenta el año anterior a la crisis del covid19 fue bautizado por la prensa internacional como "el año de la protesta" 1 y que el incremento progresivo de la actividad de los levantamientos populares en los últimos años nos situaría ya, según recientes estudios sobre seguridad nacional, "en una era de protestas políticas masivas sin precedentes históricos por su frecuencia, alcance y dimensión"2. Apenas unos meses después, las imágenes de las calles y plazas desiertas se extendían como un filtro vintage sobre el recuerdo de levantamientos populares que exigían democracia, justicia distributiva o ambas cosas a la vez.

Al mismo tiempo, la presencia ubicua de las fuerzas de seguridad resulta demasiado familiar, como si no mediaran apenas distancias entre el presente escenario y los de la represión de la protesta callejera. ¿Cómo interpretar esa disonancia? Por supuesto, la crisis sanitaria proporciona un marco muy concreto para la interpretación del papel jugado por las

${ }^{1}$ RACHMAN, 2019: the Year of Street Protest, Mass demonstrations around the globe show no sign of fizzling out.
2 BRANNEN, HAIG, SHCMIDT, The Age of Mass Protests. Understanding an Escalating Global Trend,p. 1. 
fuerzas de seguridad en el ordenamiento cotidiano del espacio público. No obstante, si atendemos a lo que la presencia de las fuerzas de seguridad representa en términos de exposición a la violencia de determinados colectivos pone en evidencia la existencia de ciertas contigüidades entre ambos escenarios. De hecho, como en otros periodos de emergencia o de alarma, esta violencia ha estado dirigida también contra diferentes formas de protesta urbana. Teniendo estas relaciones en cuenta, y en vista del apoyo creciente con que parece contar el proceso global de securitización de las políticas de salud pública, cabe preguntar ¿queda algún espacio de legitimidad para la pregunta por las relaciones entre la represión de la protesta urbana y la securitización de la salud pública? ¿O son acaso los virus, necesariamente, contrarrevolucionarios?

\section{Biopolíticas del orden público}

Como aproximación, quería plantear una comparación entre el ciclo de levantamientos populares iniciado por la Primavera Árabe y los del pasado año. Como sabemos, el primero adquirió un alcance pandémico a través de contagios que llevaron al 15-M, a la ocupación de la plaza Sintagma, al Occupy Movement, el Occupy Central en Hong Kong o la resistencia del Parque Gezi, entre otros movimientos que deben su aire de familia a su manera de disputar s espacio público mediante el uso de la desobediencia civil para reclamar el derecho a ocupar el espacio público ${ }^{3}$. Frente a estas, las recientes protestas desde el mismo Hong Kong hasta las de Chile, pasando por las jornadas de los Chalecos Amarillos en Francia o las noches del Tsunami Democratic en Barcelona nos han dejado, con frecuencia, imágenes antagónicas con las de las estoicas sentadas bajo las lluvias de golpes en el 15-M o bajo la lluvia de gas pimienta en el Movimiento Occupy. Sin duda, sería un grave error obviar la enorme capacidad para la desobediencia civil pacífica desplegada en cualquiera de esos últimos movimientos. Pero no lo sería menos, en mi opinión, obviar los contrastes existentes entre ambos ciclos.

¿Cambio en las estrategias o mayores grados de manipulación mediática? Probablemente, ambos factores deban ser tenidos en cuenta, aunque ninguno se encuentre entre los decisivos. Mucho menos se debería el contraste a una hipotética mayor laxitud en la represión estatal. Por el contrario, las protestas del pasado año se enfrentaron con frecuencia a dispositivos securitarios mucho más restrictivos que sus predecesoras, entre otras cosas porque se alzaban sobre la reacción autoritaria que suscitaron aquellas. La minuciosa criminalización de la desobediencia civil en el espacio público o virtual por parte de la ley mordaza en España resulta, a este respecto, paradigmática ${ }^{4}$. Algo muy similar sucedía en lugares como Francia, donde los estados de urgencia declarados para hacer frente a amenazas terroristas se emplearon sistemáticamente para reprimir la protesta social ${ }^{5}$; o en Brasil, donde las Jornadas de Junio de 2013 fueron respondidas con una ley antiterrorista con un gran potencial para criminalizar formas pacíficas de protesta, ahora en manos del gobierno de Jair Bolsonaro. A lo largo y ancho del globo, las protestas condujeron a un ciclo punitivo, combinado con frecuencia con los intentos de restauración del orden moral de la mano de las nuevas extremas derechas.

Podría parecer contradictorio que las perturbaciones del orden público hayan sido más violentas en condiciones más represivas. En la práctica, lo contrario parece ser cierto. El grado de autoritarismo desplegado en la respuesta a la desobediencia civil tiende a ser proporcional a la del estallido social que acompaña su ejercicio. Desde ese punto de vista, los adoquines arrancados del suelo de Barcelona durante el Tsunami Democratic serían un eco tardío de la violencia del desalojo de la Plaza Cataluña y de la represión judicial subsiguiente, las jornadas

3 PICKERILL, KRINSKY, Why Does Occupy Matter?, p. 180.

${ }^{4}$ MAQUEDA ABREU, La criminalización del espacio público, p. 12.

5 CODACCIONI, L'Etat d'urgence En France Monitor Racism. 
de los chalecos amarillos de la represión policial de la Nuit Debut, las protestas de 2019 en Hong Kong, de la criminalización del Occupy Central with Love and Peace, y las primaveras latinoamericanas de 2019, de la represión de la protesta en múltiples escenarios austericidas. En términos cinematográficos, la sonrisa de El Joker solo resulta legible sobre el trasfondo de la criminalización de la máscara de $\mathrm{V}$ de Vendetta.

Entre estas reacciones autoritarias, destaca una que guarda una relación muy directa con la respuesta por múltiples gobiernos a la crisis del covid19, a saber, la proliferación de variaciones de la figura del estado de excepción. Esto es, variaciones de la forma en que el estado de derecho prevé, en un interior del marco jurídico, las formas, procedimientos, los plazos y los grados en que en que este puede verse desplazado por una suspensión de derechos fundamentales y de la separación de poderes. 0, como lo expresa Agamben en el estudio titulado justamente El estado de excepción, las formas en que una cierta exterioridad a la propia legislación se reviste, no obstante, de una forma jurídica ${ }^{6}$. No me refiero, en este sentido, tan solo a los estados de excepción declarados en cuanto tales y con ese preciso nombre sino, más bien, al estado de excepción como familia de suspensiones del orden jurídico ordinario de una democracia cuyos límites y contornos se ven forzados, transgredidos y redefinidos en nombre de diferentes cláusulas y regímenes de excepcionalidad. Lo hizo Hong Kong, dotando a la Jefa Ejecutiva poderes ilimitados al margen del parlamento, lo hizo Ecuador para lanzar al ejército sobre el movimiento indígena y lo hizo el presidente Piñera, en Chile, con el argumento de que la población había entrado en guerra contra el estado. Sobre un estado de excepción militarizado se erigió también el gobierno de transición de Bolivia y como estado de excepción permanente califica Amnistía Internacional al sistema de justicia paralelo con que la Junta Suprema de Seguridad de Egipto persigue la disidencia pacífica para garantizar que "lo que sucedió siete u ocho años atrás [la Revolución Egipcia] no volverá a suceder"7. Todo ello sin olvidar que, como recuerda Agamben, la lógica del estado de excepción se confunde con frecuencia con el orden cotidiano de la democracia ${ }^{8}$, como lo puso recientemente de manifiesto la justicia española al acusar a activistas sociales de Cataluña de un anacrónico delito contra el orden público llamado sedición y que carga en sí mismo todo el peso del estado de excepción.

Por lo que a la distinción entre democracia y sus opuestos se refiere, el alcance de esta tensión entre la posibilidad del desorden público y el estado de excepción no es en absoluto menor. Baste recordar, como lo hace Judith Butler releyendo Hannah Arendt, que del carácter público del espacio público depende nuestra capacidad para articular sujetos políticos plurales y demandas colectivas ${ }^{9}$, esto es, más allá de los estrechos márgenes de la democracia representativa. De ahí que resulte tan importante tener en cuenta la violencia direccionada contra colectivos específicos a la hora de analizar cualquier escenario de represión policial, pues conducen a todo tipo de fragmentaciones internas de los estados de excepción. Así lo han puesto en evidencia la presión policial contra las comunidades islámicas durante los estados de urgencia de París, las denuncias del movimiento \#MeToo contra la violencia de la policía de Hong Kong o la performance del colectivo Las Tesis, de Chile, entre otros compromisos similares del derecho a la ciudad y a la protesta.

Sirvan estos pocos ejemplos para recordar que el orden del espacio público restituido por el estado de excepción implica siempre un determinado orden de clase, racial, de género y sexual. En otros términos, todo estado de excepción se expresa mediante una determinada

\footnotetext{
${ }^{6}$ AGAMBEN, State of Exception,p. 33. La ambivalencia entre el carácter interno (Schmitt) o externo (Benjamin) al cuerpo jurídico de esta figura es un asunto ampliamente debatido en los límites entre la Filosofía Politica y la Filosofía del Derecho. Para una aproximación jurídica a esta tensión en el escenario posterior al 11 de septiembre ver FLORES DÍAZ, El estado de excepción en la época actual.

${ }^{7}$ AMNESTY INTERNATIONAL, Permanent State of Exception, p. 13.

${ }^{8}$ AGAMBEN, State of Exception,p. 18.

9 BUTLER, Notes Toward a Performative Theory of Assembly, pp. 59, 72-74.
} 
biopolítica del orden público ${ }^{10}$. Dicho de otro modo, si entendemos la biopolítica en los términos del Foucault de Defender la Sociedad, como un conjunto de cálculos y operaciones del poder que toman al cuerpo individual como cuerpo vivo y, al mismo tiempo, como parte de ese "cuerpo múltiple, cuerpo de muchas cabezas, si no infinito, al menos necesariamente innumerable"11 de la población, ¿podría existir una biopolítica que no implicase una determinada distribución de los cuerpos en el espacio público? ¿Una biopolítica que no fuese, siempre ya, un régimen de su circulación en el espacio urbano? En cierto modo, esto es lo que se derivaría de la atención dedicada por Foucault a los espacios disciplinarios y a la distribución de los cuerpos en el hospital o la prisión como punto de partida para la comprensión de una forma diferente de poder, correspondiente a una biopolítica extramuros. Este sería, además, el motivo por el que cualquier delimitación de las fronteras entre la democracia y sus opuestos depende de la pregunta previa por quién puede circular por el espacio público, con qué limitaciones, enfrentando qué riesgos. Al fin y al cabo, por la organización política de las polis griegas sabemos que los regímenes de permeabilidad del ágora pública coincidían con los de la democracia para mujeres, esclavos, o quienes quebraban los mandatos de la moral sexual, como pone en evidencia la acusación de prostitución dirigida contra el ateniense Timarco ${ }^{12}$. Algo similar sería, por su parte, lo que nos sugiere Jasbir Puar al interpretar las limitaciones impuestas a la movilidad del cuerpo racializado en función del nivel de amenaza terrorista u homofóbica que pueda representar en el mercado global de la democracia13; esto es, según la posición que ocupe en diferentes regímenes de excepcionalidad. Así las cosas, bien puede ser que lo que llamamos democracia no sea sino una intersección entre diferentes estados de excepción.

\section{Securitización global}

Resulta evidente, a estas alturas, que el covid19 ha caído como meteorito sobre la tensión previamente establecida entre la ola global de protestas y los estados de excepción declarados para hacerles frente. Torciendo la balanza del lado de los segundos, los estados de emergencia, alarma, calamidad, catástrofe, de sitio y de excepción propiamente dichos han acallado las calles con unos niveles de apoyo social que resultaban impensables hace tan solo unos meses. Profetas del darwinismo neoliberal aparte, ¿quién renunciaría a la tarea de salvar vidas por no renunciar a cualquier conjunto de derechos fundamentales? Además de este argumento moral, la primacía del enfoque punitivista, la acumulación de poderes extraparlamentarios y la militarización de la respuesta se encuentran salvaguardadas por un cerrado círculo vicioso: si el estado de excepción tiene éxito en mitigar la crisis, será solo suyo, si no lo hace, será tan solo porque la situación requería medidas aún más extremas. Ante esta disyuntiva, y tomando en serio la tradición de la teoría crítica que, desde Walter Benjamin hasta Michael Hardt y Antonio Negri, nos advierte de la vocación de todo estado de excepción por convertirse en norma, cabe preguntarse, ¿en qué situación se encuentra el proceso de normalización de este estado de excepción? ¿Y en qué medida nos situaría su vertiente humanitaria en terreno desconocido, y en cuál extiende regímenes de excepcionalidad previamente consolidados?

Cabe señalar, en primer lugar, que la inflación securitaria de la respuesta sanitaria parece lejos de haber sido improvisada. Así lo sugiere el impulso dado a las políticas de seguridad global de la OMS en los últimos años y, en especial, las directrices de la Junta de Vigilancia Mundial de la Preparación ${ }^{14}$ publicadas en septiembre de 2019 ante el riesgo de

\footnotetext{
10 PÉREZ NAVARRO, Biocriminality and the Borders of Public Order.

11 FOUCAULT, Defender la sociedad, p. 222.

12 FOUCAULT, Historia de La Sexualidad. El Uso de Los Placeres, p. 201.

13 PUAR, Terrorist Assemblages, p. 3.

14 JUNTA DE VIGILANCIA, Un mundo en peligro.
} 
que liberación de un virus respiratorio letal pudiese segar millones de vidas y frenar la economía mundial hasta en un 5\%. Dos meses después, los diferentes gobiernos iniciaban una suerte de competición en la implementación de las respuestas securitarias al covid19. No parece demasiado aventurado pensar que la Junta de Vigilancia pueda haber sido una influencia decisiva en la securitización de la gestión global de la crisis. Especialmente, teniendo en cuenta que fue creada a instancias de las Naciones Unidas y que está integrada por representantes de organismos tan influyentes como la OMS, la Fundación Gates, la Asociación de Medicina de Estados Unidos o el Centro para la Prevención y el Control de Enfermedades de China, sin olvidar a grandes compañías de seguros como la fundación Chile UC Christus. La predilección de este organismo por la primacía de la dimensión securitaria en la gestión de las crisis sanitarias resulta, por lo demás, evidente. Baste referir aquí el informe de la Junta de Vigilancia publicado en julio de 2019 en el que se defiende la militarización de las alarmas sanitarias, la movilidad de los ejércitos y la coordinación entre sistemas públicos y privados de seguridad ${ }^{15}$. Sea cual sea, en la práctica, el alcance de estas directrices, lo que parece innegable es que su discurso se corresponden bastante bien con un escenario en el que la movilidad de pacientes entre países vecinos se enfrenta a serias limitaciones mientras el ejército estadounidense despliega sus tropas por toda Europa en coordinación con la OMS ${ }^{16}$ sin encontrar ningún tipo de obstáculo.

Todo ello no pasaría del orden de lo inquietante si no fuera porque parece existir una distancia creciente entre el paradigma securitario y la política sanitaria en cuanto tal. Así lo constatan incluso los informes de la Junta de Vigilancia cuando recogen la preocupación de un experto anónimo por el absoluto divorcio institucional existente entre el programa de seguridad sanitaria global de la OMS y las políticas dirigidas al refuerzo de la calidad, la capacidad y la universalidad de los sistemas de salud pública, lo que vendría a convertir al primero en "un programa vertical más"17. Los diferentes gobiernos, por su parte, parecen haber tenido pocas dificultades en sumarse a un paradigma de securitización de la salud pública en el que encuentran una estrategia de compensación, tanto material como simbólica, a las deficiencias de la respuesta sanitaria. Lo tardío de las respuestas, en especial, ha venido a incrementar exponencialmente unos grados de autoritarismo en la imposición de las cuarentenas que contrastan vivamente con la timidez de las medidas tomadas a la hora de poner al sector privado al servicio de la salud pública. Destacan, en entre estos, casos como el de Ecuador, donde los toques de queda incluyen amenazas de prisión. 0 el del estado español, convertido en uno de los epicentros de la tormenta pandémica mientras el debate político se ha centrado en dirimir si se implementó o no a tiempo el confinamiento obligatorio más restrictivo de Europa, al amparo de la misma ley mordaza con que se reprimía la protesta social y cuyo proceso de derogación se ha visto interrumpido por una suerte de lavado de cara sanitario de última hora.

Sobre esas premisas, el estado de excepción ha demostrado con creces su capacidad para extender su inhóspita lógica a la relación social, convirtiendo las más diversas fracturas sociales en profundos abismos. Los días alternos en que hombres y mujeres pueden pisar las calles en Perú o Panamá son una muestra extrema, con un obvio potencial para cristalizar en violencias específicas contra la población trans. Dramática resulta también la situación de los pueblos indígenas y afrodescendientes de América Latina que hacen frente al covid19 en condiciones de vulnerabilidad extrema a las que se suma la brutalidad racista y patriarcal que conlleva la presencia de las fuerzas armadas en sus territorios, frente a la que se han posicionado ya más de cien organizaciones de Ecuador, Colombia, Brasil, Argentina, Chile, Venezuela, México, Uruguay, Guatemala, Paraguay, Haití y Bolivia ${ }^{18}$. En el caso de España, la

\footnotetext{
15 JUNTA DE VIGILANCIA, The state of governance and coordination for health emergency preparedness, p. 42.

16 OTAN, Defender Europe-20, Health and Welfare are Priority.

17 JUNTA DE VIGILANCIA, The state of governance and coordination for health emergency preparedness, p. 35.

18 CONAIE, Llamamiento de los pueblos originarios y afrodescendientes de América Latina.
} 
cuarentena con gastos pagados de las turistas del hotel en Tenerife y el hostigamiento policial y las amenazas de desproporcionadas multas a las familias gitanas de Haro, en la Rioja, marcó el tempo de una cuarentena en la que las variables raciales y de clase se adaptan con facilidad a las nuevas coordenadas biopolíticas. Pensemos si no en el contraste entre los vuelos de repatriaciones y los deportaciones en tiempos de cuarentena, en el aumento de la presión policial en barrios periféricos y en las denuncias de sus actuaciones racistas, machistas, transfóbicas y capacitistas; sin olvidar la fractura social generada entre quienes teletrabajan y quienes lo hacen a domicilio, entre quienes son contemplados con mayor o menor éxito en las medidas extraordinarias del gobierno y quienes, como las trabajadoras del sexo, permanecen siempre al margen de las mismas.

Al mismo tiempo, la lógica belicista ha venido a dotar de un aura de civismo a una estigmatización de diversos colectivos que, modulando la amenaza del contagio en relación con racismos y moralismos varios, sufrió en primer lugar la población de origen asiático y de la que el panóptico vecinal para el escrutinio de todo tipo de movimientos, comportamientos y actitudes constituiría, por su parte, su expresión más sofisticada. La biopolítica del orden público en tiempos de pandemia subraya así la función atribuida por Foucault al racismo como paradigma de la función de muerte, literal o simbólica, en la "sociedad de normalización"19. A nadie escandaliza, en consecuencia, que la policía pueda irrumpir en un domicilio privado donde un grupo de personas se habría reunido para drogarse y tener sexo mientras que se considera perfectamente legal abandonar el domicilio para congregarse en misa. La ausencia de medidas para mitigar los efectos del arresto domiciliar de la infancia parece igualmente difícil de entender, por su parte, sin tener en cuenta su generalizada percepción como amenaza de transmisión asintomática. Incluso la preocupación por la protección de la tercera edad se ha visto algo más que empañada por la desidia letal de las residencias privadas o las pedradas lanzadas contra un autobús que transportaba ancianos a una residencia en La Línea. Poco sorprende que en ese contexto se redacten protocolos bioéticos señalando el "valor social de la persona enferma" 20 como criterio de admisión en las unidades de cuidados intensivos, invitando así al equipo médico a sumarse a la moral de excepción propia de los estados totalitarios a la hora de elegir si enviar primero a la UCI a una presidiaria, a un abogado, o a un mantero sin papeles. Si algo define al estado de excepción es, precisamente, la quiebra del principio democrático según el cual todas tenemos el mismo valor social o el derecho, al menos, a ser tratadas como si lo tuviéramos.

\section{El espacio de la protesta}

Sería un error ignorar las formas en que la ética de la covulnerabilidad se abre paso, contra viento y marea, en el contexto de crisis. Su rastro resulta evidente en la disposición del personal sanitario a trabajar en condiciones penosas y de riesgo por la falta de recursos, en la producción en red de material sanitario o en la organización vecinal para suplir a unos servicios sociales diezmados por los recortes, por citar solo algunos ejemplos. No obstante, es posible que nuestra relación general con la pandemia tenga mucho menos que ver con la solidaridad que con los mandatos de una moral de excepción basada ante todo en el miedo, la sumisión a la autoridad y la construcción del otro como amenaza, todo ello auspiciado por un discurso mediático que, como recordaba también la Junta de Vigilancia, juega un papel crucial a la hora de condicionar la reacción social en escenarios de pandemia. Pensemos si no, para ilustrar este extremo, que la cifra de migrantes muertos en el Mediterráneo desde 2014 supera a la de muertes combinadas por covid19 entre España e Italia a finales del mes de marzo ${ }^{21}$, sin que esta cifra ocupara ni un mínima parte de la que le correspondió a la

\footnotetext{
${ }^{19}$ FOUCAULT, Defender La Sociedad. Curso En El College de France (1975-1976), p. 231.

20 SEMICYUC, Recomendaciones éticas para la toma de decisiones en la situación de crisis por pandemia, p. 12.

21 ONU, Los migrantes muertos en el Mediterráneo desde 2014 suman más de 20.000.
} 
pandemia. El contraste entre nuestra tolerancia ante una respuesta institucional que, en un caso, criminaliza los rescates y, en el otro, extrema las precauciones, no habla demasiado bien de nuestra empatía con la población más vulnerable. Lo hace bien alto, más bien, del imperio de una racionalidad biopolítica llamada racismo de estado.

Estos contrastes guardan relación con la dimensión metafórica de la enfermedad a la que se refiere Susan Sontag al respecto del sida ${ }^{22}$ y que sobrepasa el campo de lo sanitario en dirección a la biopolítica. En el caso del covid19, la amenaza pandémica se presenta como una guerra contra un mal absoluto, divorciada de cualquier punto de referencia por comparación con otras enfermedades, otras pandemias, otros factores de riesgo y otras tragedias humanitarias. Más allá del restringido ámbito de las estrategias de prevención, la pedagogía epidemiológica brilla por su ausencia en el discurso mediático, contribuyendo a crear una pura y simple sensación de pánico poco dada al pensamiento crítico y muy favorable al refugio autoritario. Como resultado, lo ominoso de la pandemia cercena nuestra capacidad de pensar que las alternativas sean siquiera posibles, compensando con creces la pérdida de confianza en las instituciones señalada en las directrices de la Junta como un obstáculo a superar en los periodos de alerta sanitaria.

Sin lugar a dudas, la desconfianza existe, hunde sus raíces en el ciclo iniciado por la Primavera Árabe y se extiende hasta levantamientos mucho más recientes. Y parece estar, además, de sobra justificada teniendo en cuenta que la violencia estatal desplegada como respuesta a dichas protestas ha venido a respaldar la multitud de procesos de ajustes, recortes y privatizaciones que conducen al estrecho margen de maniobra con que enfrentamos la presente crisis. En ese sentido, el avance de la agenda neoliberal es el telón de fondo que explica la prolongación de la primacía de lo securitario desde los escenarios de protesta hasta los de pandemia. Dicho de otro modo, el autoritarismo desplegado en la defensa del orden público y la securitización de la salud global forman parte de uno y el mismo estado de excepción, que además se extenderá durante un austericidio pos-Covid-19 en el que perderemos, literalmente, la cuenta de las bajas. Mientras dure, discutiremos sobre los medios y las estrategias, sobre la mejor forma de protegernos a nosotras mismas y a las más vulnerables de entre nosotras, sobre cómo articular la condena de la violencia con la urgencia de responder ante ella. La batalla decisiva será, sin embargo, la que libremos para recuperar el espacio de la protesta.

\section{Referencias}

AGAMBEN, G. State of Exception. Chicago: The University of Chicago Press, 2005.

AMNESTY INTERNATIONAL, Permanent State of Exception. Abuses by the Supreme State Security Prosecution. London, 2019. Disponível em <https://www.amnesty.org/download/Documents/MDE1213992019ENGLISH.pdf>. Acesso em 14 de abril e 2020.

BRANNEN, S., HAIG, C., SHCMIDT, K., The Age of Mass Protests. Understanding an Escalating Global Trend. Washington D.C.: Center for Strategic and International Studies. Disponível em: <https://www.csis.org/analysis/age-mass-protests-understanding-escalating-global-trend>. Acesso em 14 de abril e 2020.

BUTLER, J. Notes Toward a Performative Theory of Assembly. London: Harvard University Press, 2015.

${ }^{22}$ SONTAG, La Enfermedad y Sus Metáforas. El Sida y Sus Metáforas. 
CODACCIONI, V. L'Etat d'urgence En France: Profilage et Régime d'exception Discriminatoire, Monitor Racism, 2018. Disponível em: <http://monitoracism.eu/etat-durgence-en-france/>. Acesso em 14 de abril e 2020.

CONAIE, Llamamiento de los pueblos originarios, afrodescendientes y las organizaciones populares de América Latina, 1 de abril de 2020. Disponível em > https://conaie.org/2020/04/06/llamamiento-de-los-pueblos-originarios-afrodescendientesy-las-organizaciones-populares-de-america-latina/>. Acesso em 14 de abril e 2020.

FLORES DÍAZ, El estado de excepción en la época actual. Apuntes Electorales. Revista del instituto electoral del estado de México, v. 50, 2014, pp. 43-86.

FOUCAULT, M. Defender la sociedad. Curso en el college de france (1975-1976). Buenos Aires: Fondo de Cultura Económica de Argentina, 2000.

FOUCAULT, M. Historia de La Sexualidad. El Uso de Los Placeres. Siglo XXI Editores, 1998.

MAQUEDA ABREU, M. La Criminalización Del Espacio Público: El Imparable Ascenso de Las “Clases Peligrosas". Revista Electrónica de Ciencia Penal y Criminología, v. 12, 2015.

JUNTA DE VIGILANCIA MUNDIAL DE LA PREPARACIÓN. Un mundo en peligro - Medidas que deben adoptar los dirigentes. World Health Organization, Geneva, 2019.

JUNTA DE VIGILANCIA MUNDIAL DE LA PREPARACIÓN. The state of governance and coordination for health emergency preparedness. Oxford: University of Oxford, 2019. Disponível em: <https://apps.who.int/gpmb/thematic report.html>. Acesso em 14 de abril e 2020.

OTAN. Defender Europe-20. SHAPE Public Affairs Office, 23 de marzo de 2020. Disponível em: $<$ https://shape.nato.int/defender-europe/defender/newsroom/defendereurope-20-healthand-welfare-are-priority>. Acesso em 14 de abril e 2020.

ONU. Los migrantes muertos en el Mediterráneo desde 2014 suman más de 20.000. ONU Noticias, 5 de marzo de 2020. Disponível em: <https://news.un.org/es/story/2020/03/1470681>. Acesso em 14 de abril e 2020.

PÉREZ NAVARRO, P. Biocriminality and the Borders of Public Order. En: Miranda, P., Lima, A., Silva, F. (Eds.), Questioning the Oneness of Philosophy. Lisbon: Center for Philosophy at the University of Lisbon, 2018, pp. 203-214.

PICKERILL, J., KRINSKY, J. Why Does Occupy Matter? Social Movement Studies: Journal of Social, Cultural and Political Protest, v. 11. 2012, pp. 279-87. Disponível em $<$ https://doi.org/10.1080/14742837.2012.708923>. Acesso em 14 de abril e 2020.

PUAR, J. K. Terrorist Assemblages. Durham: Duke University Press, 2007.

RACHMAN, G. 2019: the year of street protest. Mass demonstrations around the globe show no sign of fizzling out. Financial Times, 23 de diciembre de 2019. Disponível em: <https://www.ft.com/content/9f7e94c4-2563-11ea-9a4f-963f0ec7e134>. Acesso em $14 \mathrm{de}$ abril e 2020.

SEMICYUC, Recomendaciones éticas para la toma de decisiones en la situación excepcional de crisis por pandemia Covid-19 en las unidades de cuidados intensivos. Sociedad Española de Medicina Intensiva, Crítica y Unidades Coronarias, 2020.

SONTANG, S. La Enfermedad y Sus Metáforas. El Sida y Sus Metáforas. Buenos Aires: Taurus, 2003. 